\title{
Influences of the resistive SFCL on the Incremental Power Frequency Relay of Transmission Lines
}

Article in IEEE Transactions on Applied Superconductivity · January 2019

DOI: 10.1109/TASC.2019.2895926

CITATIONS

7 authors, including:

Qihuan Dong

University of Cambridge

16 PUBLICATIONS 49 CITATIONS

SEE PROFILE

Xiuchang Zhang

University of Cambridge

37 PUBLICATIONS 183 CITATIONS

SEE PROFILE

Some of the authors of this publication are also working on these related projects:

Project Engineering Properties of Superconducting Materials View project
READS

6

Wescley Tiago B. de Sousa

Karlsruhe Institute of Technology

26 PUBLICATIONS 135 CITATIONS

SEE PROFILE

Jianzhao Geng

University of Cambridge

53 PUBLICATIONS 237 CITATIONS

SEE PROFILE 


\title{
Influences of the resistive SFCL on the Incremental Power Frequency Relay of Transmission Lines
}

\author{
Qihuan Dong, W. T. B. de Sousa, Jianzhao Geng, Xiuchang Zhang, Heng Zhang, Boyang Shen, Tim Coombs
}

\begin{abstract}
The superconducting fault current limiter (SFCL) has been effective in coping with large fault currents and is expected to be largely applicated in the power system to solve the problem of increasing fault current level in power grid nowadays. However, the coordination between SFCLs and traditional power system devices such as protective relaying has not been researched enough. This paper studies the influences of the resistive type SFCL on the incremental power frequency relay (IPFR) of the transmission lines. The resistive SFCL is simulated by using thermal-electric analog method; A model of a 220-kV transmission system with the incremental power frequency relay element was built and simulated with the SIMULINK MATLAB software. Three compensation methods to eliminate the negative effects of the integration of SFCL are proposed and compared. Finally, numerical simulation tests have demonstrated the correctness and validity of theoretical analyses.
\end{abstract}

Index Terms-Superconducting fault current limiter (SFCL), Incremental power frequency relay, Transmission line.

\section{INTRODUCTION}

$\mathrm{T}$ HE expansion of the power grid and the growth of the installed capacities directly lead to the increase in the vulnerability of the power system. At the same time, the voltage levels of the grid are rapidly developing, and the topologies are getting complicated. However, the circuit breakers (CBs) are not able to deal with the resultant increasing fault currents due to their limited interrupting capacity, which poses a big threat to the normal operation of the power system. Therefore, limiting short-circuit currents during the fault time has been significant to maintaining the safe and reliable operation of the power system.

To limit fault currents, many kinds of devices have been designed and adopted, such as transformers with high impedance, split bus bars, fuses and so on. The innate drawback is that they affect the stability of the power system or cause energy losses.

Qihuan Dong, Tim Coombs, Jianzhao Geng, Xiuchang Zhang, Heng Zhang, Boyang Shen are with the Electrical Engineering Division, Department of Engineering, University of Cambridge, CB3 OFA, United Kingdom (e-mail: qd210@cam.ac.uk, tac1000@cam.ac.uk, xz326@cam.ac.uk, jg717@cam.ac.uk, bs506@cam.ac.uk, hz301@cam.ac.uk).

W. T. B. de Sousa was with Institute for Technical Physics, Karlsruhe Institute of Technology, 76344 Eggenstein-Leopoldshafen, Germany (e-mail: sousa@kit.edu)

Color versions of one or more of the figures in this paper are available online at http://ieeexplore.ieee.org.

Digital Object Identifier will be inserted here upon acceptance.
Superconducting fault current limiters (SFCLs) have a negligible impedance during normal operation and are able to develop a considerably higher resistance within a very short time (less than a quarter of an AC cycle) after a fault occurs, thereby limiting the short-circuit current to a reasonable value [1]. Most superconducting fault current limiters are either of the resistive type or inductive type [2]. This paper mainly deals with the cases of resistive type SFCL.

Despite the numerous merits of SFCLs, examples of real SFCLs being used in power grids are still rare because the practical application of the SFCLs has many unsolved problems, among which the coordination between the SFCLs and protective relay is a paramount one. Protective relay is applied to detect the fault and operate to trip the circuit breakers to isolate the fault equipment [3]. According to the electrical information used by protective relay, protective relay can be divided into over-current protection, impedance protection, directional protection, differential protection and incremental power frequency type relay (IPFR) [3]. IPFR has been applied widely in the power transmission lines. Because the integration of SFCL to power grid changes the fault transient characteristics, the reliability and sensitivity of the protection relays will be challenged. Therefore, it is important to study the effects of the SFCLs on protection relays to ensure the safe operations of the power system. So far, researches on coordination of different types of SFCL with different types of protective relays, for instance, overcurrent protection, impedance protection and zero-sequence overcurrent protection have been conducted [5]-[7]. Nevertheless, most of them focused on the three-phase symmetrical short-circuit faults, while in fact faults in the power system are mainly asymmetrical faults. When an asymmetrical fault occurs, the SFCLs will make different responses in faulted phases and healthy phases, which will make the fault characteristics even more complicated. This should be studied carefully.

This paper mainly studies the influences of resistive SFCL on IPFR under circumstances of four types of short-circuited fault, including both symmetrical and asymmetrical fault. Firstly, a power transmission system without and with SFCL are simulated respectively and thus the influences brought by SFCL can be analyzed. To eliminate the negative effect of SFCL, three different coordination schemes between the SFCLs and the IPFR are proposed. Finally, the correctness of the theoretical analyses and the validity of the coordination scheme are verified by the simulation results. 


\section{WORKING PRINCIPLE AND MODELLING OF RESISTIVE SFCLS}

\section{A. Working principles of resistive SFCL}

The resistive type is the simplest one among all types of SFCLs. It is based on the 'quench' of superconducting materials. When a superconductor quenches, it transits from the superconducting state to the resistive state and at the same time its resistance rockets within extremely short time [8]. Commercial resistive SFCLs have already been installed in the grid [9].

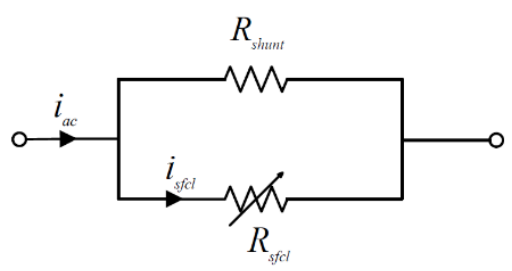

Fig. 1 Schematic of the resistive SFCL.

In order to prevent excessive heat generated by the superconductive element during the fault time in the engineering application, a shunt resistor is located in parallel with the superconductive element as shown in Fig. 1. During normal operation, the resistance of $R_{s f c l}$ is zero. It carries the entire operating current and voltage drop is zero. When a fault occurs, the temperature rise causes superconductor quench. The resistance of superconductors increases by several orders of magnitude and the shunt resistor begins to carry the majority of current [1]. In this way the superconducting element can be protected from being destroyed by heat generated by large fault current.

\section{B. Thermal-electric analogy method for R-SFCL modelling}

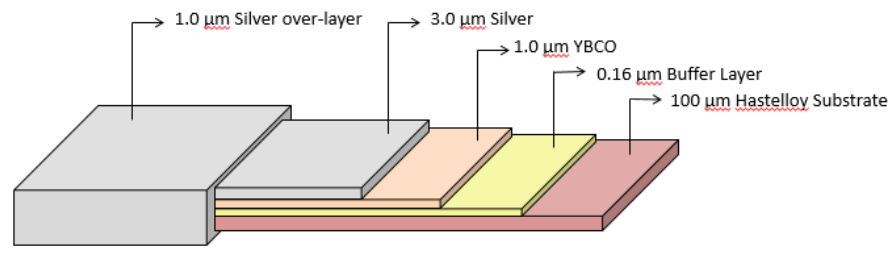

Fig. 2 Geometrical sizes of the $2 \mathrm{G}$ YBCO tapes employed in the R-SFCL model. Sizes refers to the SF12100 tapes from Superpower Inc. company.

The resistance of each layers can be calculated if the sizes of each layer and resistivity of different materials are known. Current flowing through different layers can also be calculated by Ohm's law. To simulate the transient behavior of the RSFCL, it is necessary to calculate the temperature rise of the tapes during the fault period. A reliable R-SFCL model should not only considers the heating of the HTS material but also considers the heat transfer of the HTS material with the adjacent layers as well as the heat exchanges with the surrounding environment ( $L N_{2}$ cooling bath). This makes the computation extremely difficult to implement in MATLAB. To solve the heat transfer equations inside the layers of the SFCL, a thermalelectric analogy method is used. A deep description about such method can be found in [10]. Fig.3. represents an equivalent

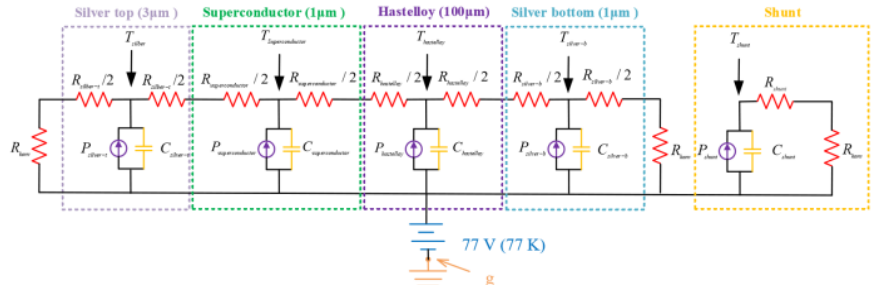

Fig.3 Equivalent thermal-electric circuit of $2 \mathrm{G}$ YBCO tape.

network that describes the thermal behavior of the R-SFCL transferred with the thermal-electric analogy method.

The R-SFCL model is composed of several coils connected in series. Each coil consists of superconducting YBCO tapes and a shunt resistor in parallel which is made of stainless steel. The number of the coils are 33, 65, 98, 135, 168, 205 respectively for resistance of $5 \Omega, 10 \Omega, 15 \Omega, 20 \Omega, 25 \Omega$ and $30 \Omega$ SFCL. Each HTS module consists of 5 tapes disposed in an anti-parallel arrangement to minimize its inductance. By designing the coils with 5 tapes in parallel, the critical current $I_{c}$ of the device reaches $1.5 \mathrm{kA}$ (the $I_{c}$ of each tape is about $300 \mathrm{~A})$. In each module, all tapes are connected in a common center contact $\mathrm{M}$, with the advantage that the tapes better protect each other in the case of hot spots. These modules are cooled in liquid nitrogen $\left(L N_{2}\right)$ at $77 \mathrm{~K}$. The quench time of the SFCL model is less than 10 milliseconds and vary marginally for the studied six different SFCL resistance.

The main parameters of the resistive SFCL device simulated in the present work are shown in table 1.

TABLE I

SFCL PARAMETERS

\begin{tabular}{cc}
\hline \hline Parameters & Value \\
\hline Tape length & $860 \mathrm{~m}$ \\
Critical current & $1.5 \mathrm{kA}$ \\
Contact resistance & $3 \mu \pi$ \\
\hline
\end{tabular}

\section{EFFECTS OF SFCLS ON THE IPFR}

The interconnections of the power grids make the network structure of the electric power system more complicated, resulting in the decrease in the system impedance. Therefore, the fault currents increase greatly. Although SFCL is a good substitute for traditional current limiting devices as it is energy saving, practical use of SFCL still faces many problems. For instance, the application of SFCLs will influence the operation of IPFR.

\section{A. The principle of IPFR}

A simplified power system with double sources $S_{m}$ and $S_{n}$ is shown in Fig.4. When a short-circuit fault $\mathrm{F}$ occurs in the transmission line L, the whole system stays in the fault state, which could be decomposed into non-fault state and fault additional state by the principle of superposition. The electrical quantity of the fault additional state is called the fault increment. 


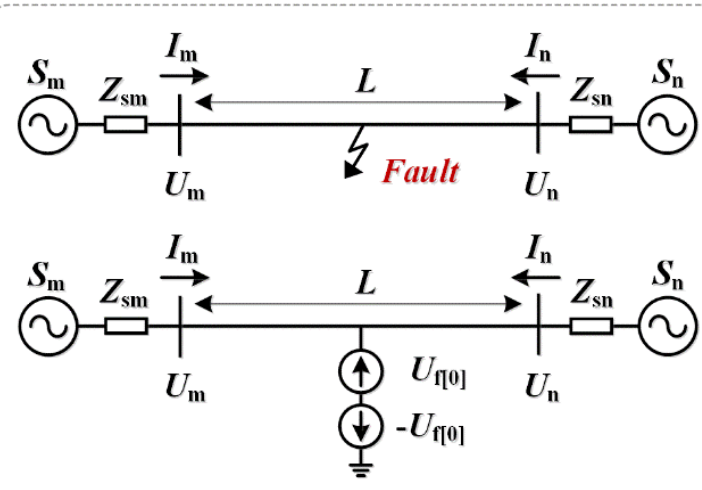

Fault State

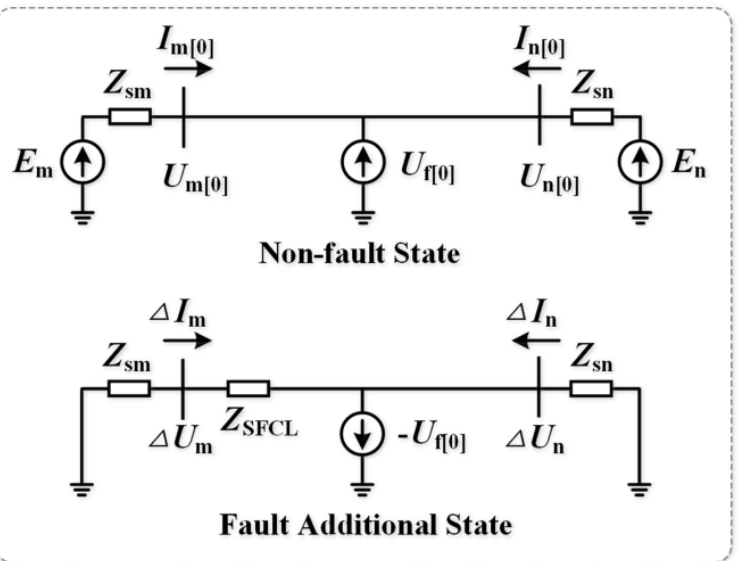

Fig.4 Diagram of power system fault decomposition.

In Fig. $4, U_{\mathrm{m}}, I_{\mathrm{m}}$ are the voltage and current of terminal $M$ in the fault state, respectively; $U_{\mathrm{m}[0]}, I_{\mathrm{m}[0]}$ are the voltage and current of terminal $M$ in the non-fault state, respectively; $\Delta U_{\mathrm{m}}$, $\Delta I_{\mathrm{m}}$ are the voltage and current of terminal $M$ in the fault additional state, respectively; and then $Z_{\mathrm{sm}}$ and $Z_{\mathrm{sn}}$ correspond to the equivalent system impedance of terminal $M$ and terminal $N$, respectively.

The fault increment can be extracted by the following equations (terminal $M$ is taken as an example):

$$
\left\{\begin{array}{l}
\Delta u_{m}=u_{m}-u_{m[0]} \\
\Delta i_{m}=i_{m}-i_{m[0]}
\end{array}\right.
$$

where the fault increment exists only in two cycles after the short-circuit fault occurs. It means the IPFR could be adopted as the main quick protective relay in the transmission lines.

The protective relay is installed at terminal $M$ and its end of protection range is $x$ (setting point), so the setting impedance is $Z_{\text {set. }}$ And the measured impedance from terminal $m$ to fault point is $Z_{\mathrm{k}}$.

1) When a positive direction fault for terminal $m$ occurs in the transmission line, the fault increment can be expressed by:

$$
-U_{f[0]}=-\Delta I_{m}\left(Z_{s m}+Z_{k}\right)
$$

Then, the fault increment at the protective relay of terminal $M$ can be presented by

$$
\Delta U_{m}=-\Delta I_{m} \cdot Z_{s m}
$$

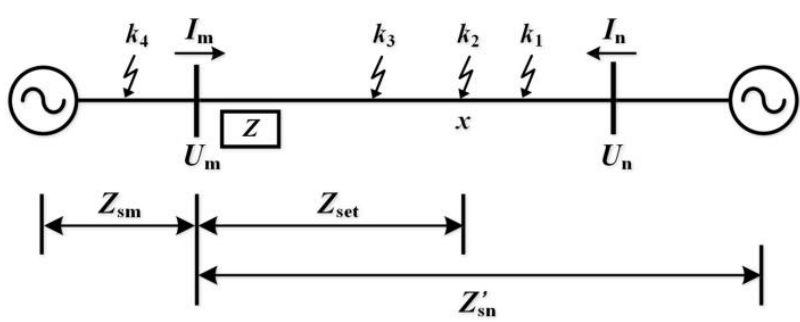

(a)

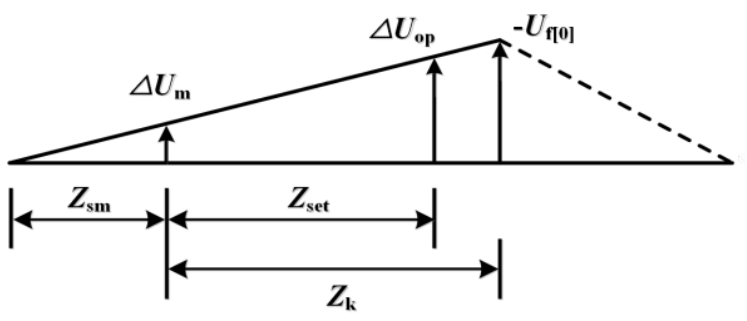

(b)

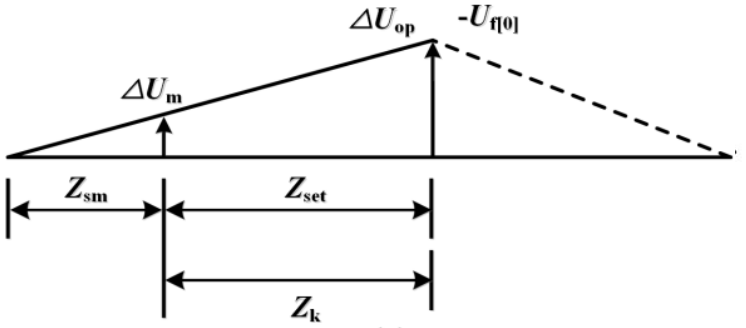

(c)

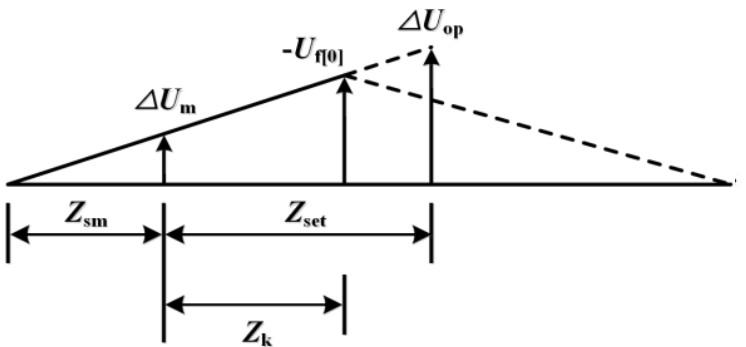

(d)

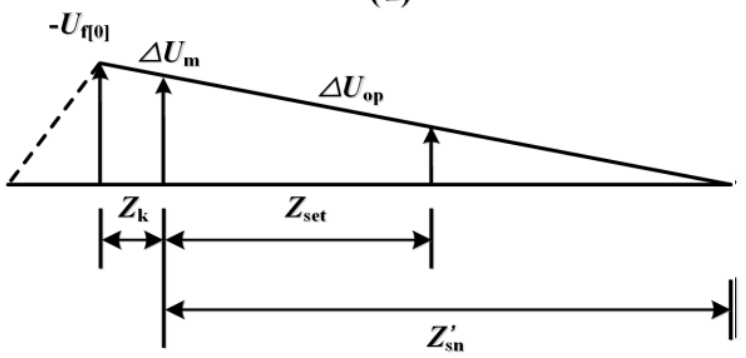

(e)

Fig.5 Voltage fault increment distribution diagram. ((a) Fault locations at the grid, (b) Positive external fault $k_{1}$, (c) Fault at setting point $k_{2}$, (d) Internal fault $k_{3}$, (e) Reverse direction fault $k_{4}$ )

According to the formula (2) and (3), the relationship between $\triangle U_{\mathrm{OP}}$ and $-U_{\mathrm{f}[0]}$ is expressed by:

$$
\Delta U_{O P}=\Delta U_{m}-\Delta I_{m} \cdot Z_{s e t}=-\frac{Z_{s m}+Z_{s e t}}{Z_{s m}+Z_{k}} U_{f[0]}
$$

From the above formula, it can be seen that:

a) When a fault out of protection range (like $k_{1}$ point) occurs, 
$Z_{\mathrm{k}}>Z_{\mathrm{set}}$, then $\left|\Delta U_{\mathrm{OP}}\right|<\left|U_{\mathrm{f}[0]}\right|$, as shown in Fig. 5b;

b) When a fault at the end of protection range (like $k_{2}$ point) occurs, $Z_{\mathrm{k}}=Z_{\mathrm{set}}$, then $\left|\Delta U_{\mathrm{OP}}\right|=\left|U_{\mathrm{f}[0]}\right|$, as shown in Fig. $5 \mathrm{c}$;

c) When a fault within the protection range (like $k_{3}$ point) occurs, $Z_{\mathrm{k}}<Z_{\mathrm{set}}$, then $\left|\Delta U_{\mathrm{OP}}\right|>\left|U_{\mathrm{f}[0]}\right|$, as shown in Fig. $5 \mathrm{~d}$;

2) When a reverse direction fault (like $k_{4}$ point) for terminal $M$ occurs, the voltage fault increment of the transmission line gradually decreases from the fault point to the neutral point at the opposite side, and the current fault increment flows from the bus to the line (as shown in Fig. 5e), then

$$
\begin{gathered}
-U_{f[0]}=\Delta I_{m}\left(Z_{s n}^{\prime}+Z_{k}\right) \\
\Delta U_{m}=\Delta I_{m} \cdot Z_{s n}^{\prime}
\end{gathered}
$$

According to the formula (5) and (6), the relationship between $\Delta U_{\mathrm{OP}}$ and $-U_{\mathrm{f}[0]}$ is expressed by:

$$
\Delta U_{O P}=\Delta U_{m}-\Delta I_{m} \cdot Z_{s e t}=-\frac{Z_{s n}^{\prime}-Z_{s e t}}{Z_{s n}^{\prime}+Z_{k}} U_{f[0]}
$$

Obviously, the operation voltage $\left|\Delta U_{\mathrm{OP}}\right|$ is greater than fault voltage $\left|U_{\mathrm{f}[0]}\right|$ for an inner fault; Conversely, $\left|\Delta U_{\mathrm{OP}}\right|$ is always smaller than $\left|U_{\mathrm{f}[0]}\right|$ for an external fault.

\section{B. Effects of the SFCLs on the IPFR}

The SFCL does not present any impedance in the normal operation and thus will not affect the running of the power system. When a short-circuit fault happens, it rapidly transitions to high impedance state to limit the fault current. Therefore, the integration of the SFCLs will affect the extraction of the fault increment, which is shown in Fig. $6 \mathrm{a}$.

In fact, the correct extraction of the fault increment with the integration of SFCLs should be presented by the schematic diagram (like Fig. 6b). However, the SFCL is negligible for the power system in the non-fault state (like Fig. 6a), which directly leads to the deviation of the extraction of the fault increment. This should be considered carefully

$$
\begin{aligned}
\Delta U_{m}^{\prime \prime} & =U_{m}-U_{m[0]}=U_{m}-U_{m[0]}^{\prime}+U_{m[0]}^{\prime}-U_{m[0]} \\
& =\Delta U_{m}+\left(U_{m[0]}^{\prime}-U_{m[0]}\right)=\Delta U_{m}+U_{A} \\
\Delta I_{m}^{\prime \prime} & =I_{m}-I_{m[0]}=I_{m}-I_{m[0]}^{\prime}+I_{m[0]}^{\prime}-I_{m[0]} \\
& =\Delta I_{m}+\left(I_{m[0]}^{\prime}-I_{m[0]}\right)=\Delta I_{m}+I_{A}
\end{aligned}
$$

where $U_{A}=U_{\mathrm{m}[0]}^{\prime}-U_{\mathrm{m}[0]}$ and $I_{A}=I_{\mathrm{m}[0]}-I_{\mathrm{m}[0]}$.

1) When a positive direction fault for terminal $M$ occurs in the transmission line, the relationship between $\Delta U_{\mathrm{OP}}$ and $-U_{\mathrm{f}[0]}$ is expressed by:

$$
\begin{aligned}
\Delta U_{O P} & =\Delta U_{m}^{\prime \prime}+\left(-I_{m}^{\prime \prime}\right) Z_{s e t} \\
& =\Delta U_{m}-\Delta I_{m}+\left(U_{A}-I_{A} Z_{s e t}\right) \\
& =-\frac{Z_{s m}+Z_{s e t}}{Z_{s m}+Z_{k}+Z_{S F C L}} U_{f[0]}+U_{B}
\end{aligned}
$$

where $U_{B}=U_{A}-I_{A} Z_{\text {set. }}$.

2) When a reverse direction fault for terminal $M$ occurs in the transmission line, the relationship between $\Delta U_{\mathrm{OP}}$ and $-U_{\mathrm{f}[0]}$ is expressed by:

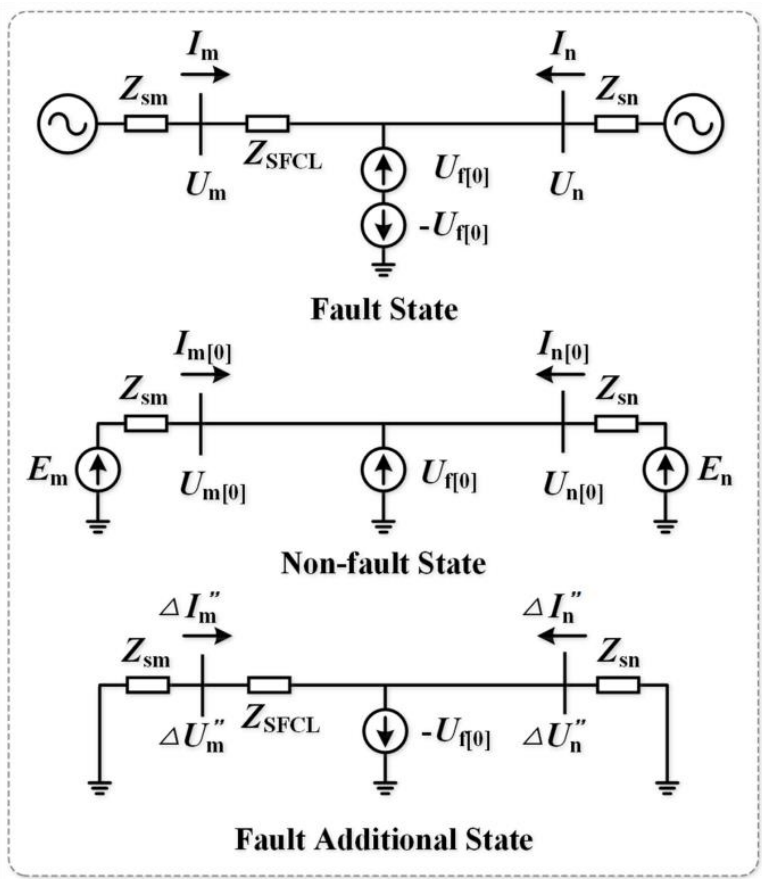

(a)

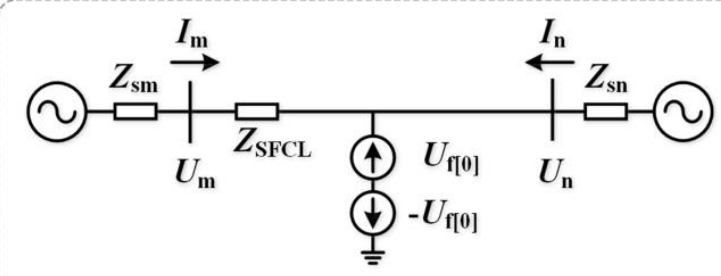

Fault State

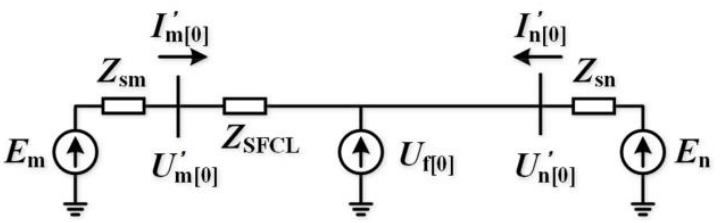

Assumed Non-fault State

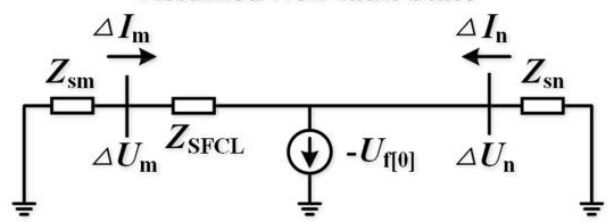

Fault Additional State

(b)

Fig. 6 Diagram of power system fault decomposition with SFCLs.

$$
\begin{aligned}
\Delta U_{O P} & =\Delta U_{m}^{\prime \prime}+\left(-I_{m}^{\prime \prime}\right) Z_{s e t} \\
& =\Delta U_{m}-\Delta I_{m}+\left(U_{A}-I_{A} Z_{s e t}\right) \\
& =-\frac{Z_{s n}^{\prime}+Z_{S F C L}-Z_{s e t}}{Z_{s n}^{\prime}+Z_{k}+Z_{S F C L}} U_{f[0]}+U_{B}
\end{aligned}
$$

where $U_{B}=U_{A}-I_{A} Z_{\text {set. }}$.

Usually, the setting of $Z_{\text {set }}$ should take the impedance of SFCL $Z_{\mathrm{SFCL}}$ into consideration. Therefore, it can be seen that the existence of $U_{B}$ largely affect the relationship 


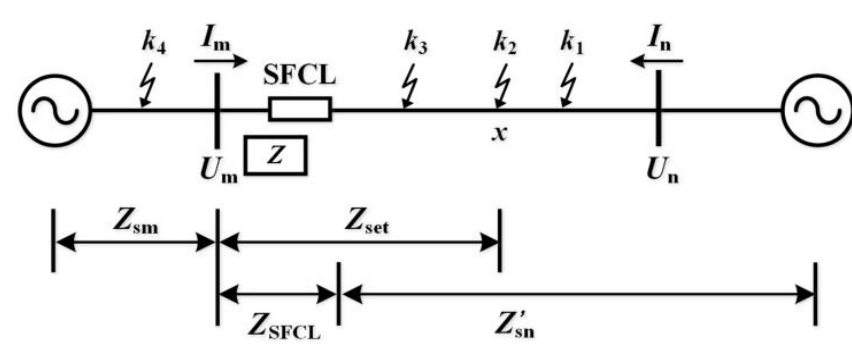

(a)

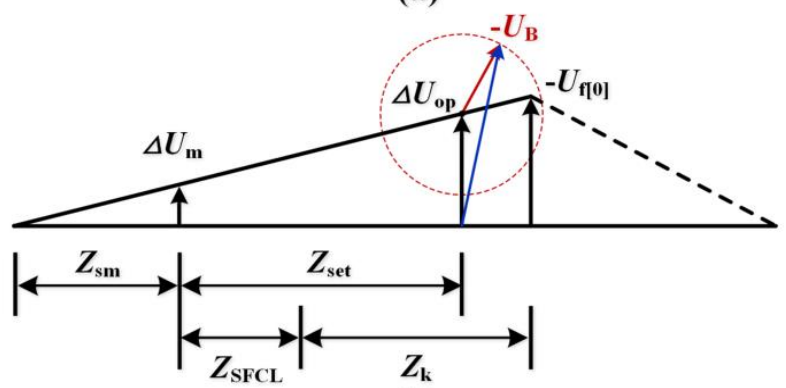

(b)

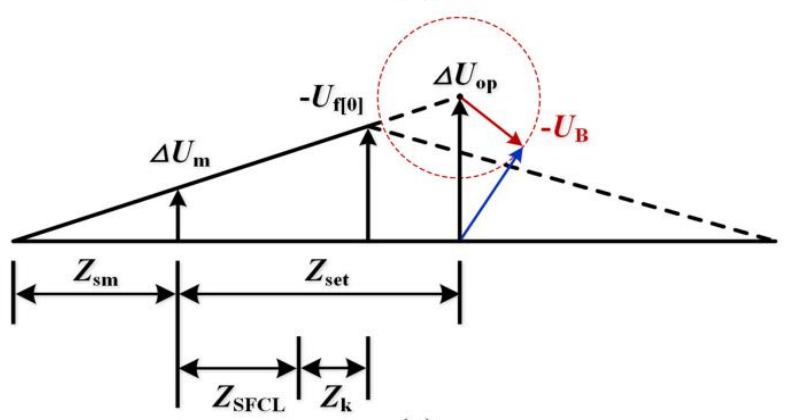

(c)

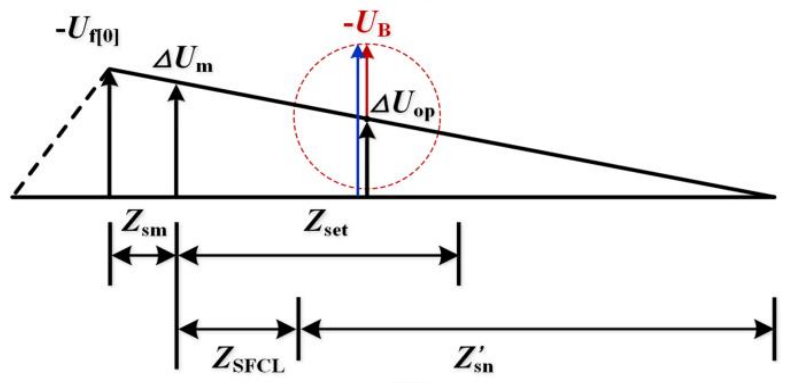

(d)

Fig.7 Voltage fault increment distribution diagram with SFCLs.

between $\Delta U_{\mathrm{OP}}$ and $-U_{\mathrm{f}[0]}$ while $U_{B}$ is influenced by the differences $U_{\mathrm{m}[0]}^{\prime}-U_{\mathrm{m}[0]}$ and $I_{\mathrm{m}[0]}^{\prime}-I_{\mathrm{m}[0]}$. And $U_{\mathrm{m}[0]}^{\prime}, I_{\mathrm{m}[0]}^{\prime}$ can be calculated when the $Z_{\mathrm{SFCL}}$ is presented in the normal operation. Then, the larger the $Z_{\mathrm{SFCL}}$ is, the bigger the differences $U_{\mathrm{m}[0]}^{\prime}-U_{\mathrm{m}[0]}$ and $I_{\mathrm{m}[0]}^{\prime}-I_{\mathrm{m}[0]}$ are. As a result, the IPFR might malfunction when it is asked not to operate and mis-operation when it is required to operate, as shown in Fig. 7.

Based on the analysis above, the installation of SFCL disrupts the relation between the operation voltage $\left|\Delta U_{\mathrm{OP}}\right|$ and fault voltage $\left|U_{\mathrm{f}[0]}\right|$. When a positive direction inner fault occurs, IPFR may misfunction; when a positive direction external fault or a reverse direction fault occurs, IPFR may malfunction.

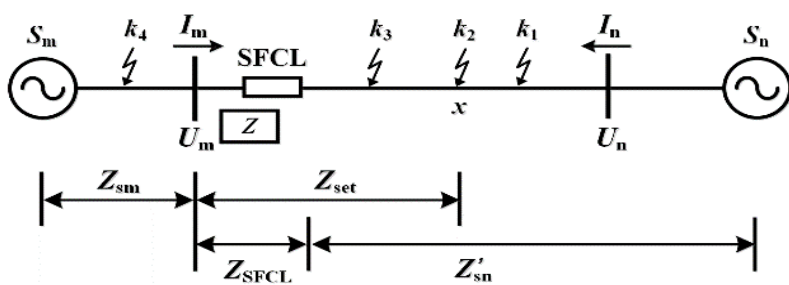

Fig.8 diagram of power system model

\section{SIMULATION ANALYSIS}

The following simulation results demonstrate the correctness and validity of theoretical analyses in the previous sections.

\section{A. Configuration of the power system}

A double sources three-phase power system is simulated in MATLAB SIMULINK and the schematic is shown in Fig.8. An IPFR device is installed near source $S_{m}$ to protect line $L_{M N}$; Meanwhile a resistive SFCL is deployed at terminal $\mathrm{M}$ to limit the short-circuited current. Parameters of the power system is listed in table 2 .

TABLE2

POWER SYSTEM PARAMETERS

\begin{tabular}{cc}
\hline \hline Parameters & Value \\
Transmission line length & $100 \mathrm{~km}$ \\
Expected protection distance & $85 \mathrm{~km}$ \\
Phase-to-phase voltage of $\mathrm{S}_{M}$ and $\mathrm{S}_{N}$ & $230 \mathrm{kV}$ \\
Phase angle of phase A of $\mathrm{S}_{M}$ and $\mathrm{S}_{N}$ & $0^{\circ}$ and $20^{\circ}$ \\
Positive sequence resistances of lines & $0.04364 \Omega / \mathrm{km}$ \\
Zero sequence resistances of lines & $0.09763 \Omega / \mathrm{km}$ \\
Positive sequence inductances of lines & $0.837 \times 10^{-3} \mathrm{H} / \mathrm{km}$ \\
Zero sequence inductances of lines & $2.983 \times 10^{-3} \mathrm{H} / \mathrm{km}$ \\
Frequency & $50 \mathrm{~Hz}$ \\
\hline
\end{tabular}

\section{B. Simulation results}

The simulation results reveal that when a positive direction inner fault occurs, IPFR misfunction. The studied fault types include symmetrical fault: three-phases $\mathrm{ABC}$ fault and unsymmetrical faults: one phase to ground AG fault, two phases BC fault and two phases to ground BCG fault. The resistance of R-SFCL ranges from $5 \Omega$ to $30 \Omega$.

Table 3-6 compare the protection distance of IPFR with and without the R-SFCL and show the protection distance of IPRF decreases with the increase of SFCL's impedance when four types of short-circuit fault occur (ABC, AG, BC, BCG) in the power system. Three methods of compensation are proposed to eliminate the negative effect of SFCL. Method I changes the setting impedance $Z_{\text {set }}$ of IPFR. It adds the impedance of SFCL directly to $Z_{\text {set }}$. The corresponding result is listed in the fourth column in Table 3-6. Method II alters both the setting impedance $Z_{\text {set }}$ and $\mathrm{K}$ factor of IPFR. In Method III, a compensation factor $\delta$ is introduced to change the setting impedance $Z_{\text {set }}$. Numerous attempts prove that when $\delta=0.85$, the protection distance can be improved to a very desirable level. 
TABLE3

INFLUENCES OF R-SFCL ON IPFR UNDER ABC FAULT

\begin{tabular}{cccccc}
\hline & \multicolumn{5}{c}{ Protection distance(km) } \\
\cline { 2 - 6 } $\begin{array}{c}\text { SFCL } \\
\text { impedance } \\
\text { value }(\Omega)\end{array}$ & $\begin{array}{c}\text { without } \\
\text { SFCL }\end{array}$ & $\begin{array}{c}\text { with } \\
\text { SFCL }\end{array}$ & $\begin{array}{c}\text { Method } \\
\text { I }\end{array}$ & $\begin{array}{c}\text { adjustment } \\
\text { Method } \\
\text { II }\end{array}$ & $\begin{array}{c}\text { Method } \\
\text { III }\end{array}$ \\
\hline 5 & 83 & 80 & 84 & 84 & 83 \\
10 & 83 & 75 & 86 & 86 & 84 \\
15 & 83 & 67 & 88 & 88 & 84 \\
20 & 83 & 56 & 90 & 90 & 84 \\
25 & 83 & 41 & 94 & 94 & 84 \\
30 & 83 & 21 & $/$ & $/$ & 84 \\
\hline
\end{tabular}

It can be seen from Table 3 that when symmetrical three phase $\mathrm{ABC}$ fault occurs in the power system, the protection distance of IPRF decrease from $80 \mathrm{~km}$ to $21 \mathrm{~km}$ with SFCL impedance rising from $5 \Omega$ to $30 \Omega$.

TABLE4

INFLUENCES OF R-SFCL ON IPFR UNDER AG FAULT

\begin{tabular}{cccccc}
\hline \hline & \multicolumn{5}{c}{ Protection distance (km) } \\
\cline { 2 - 6 } $\begin{array}{c}\text { SFCL } \\
\text { impedance } \\
\text { value }(\Omega)\end{array}$ & $\begin{array}{c}\text { without } \\
\text { SFCL }\end{array}$ & $\begin{array}{c}\text { with } \\
\text { SFCL }\end{array}$ & $\begin{array}{c}\text { Method } \\
\text { I }\end{array}$ & $\begin{array}{c}\text { adjustment } \\
\text { Method } \\
\text { II }\end{array}$ & $\begin{array}{c}\text { Method } \\
\text { III }\end{array}$ \\
\hline 5 & 83 & 83 & 87 & 84 & 84 \\
10 & 83 & 82 & 92 & 86 & 83 \\
15 & 83 & 79 & 96 & 87 & 83 \\
20 & 83 & 77 & $/$ & 89 & 83 \\
25 & 83 & 73 & $/$ & 91 & 82 \\
30 & 83 & 68 & $/$ & 94 & 83 \\
\hline
\end{tabular}

Table 4 demonstrates that for unsymmetrical one phase to ground AG fault, when the resistance of SFCL is $5 \Omega$, it hardly affects the operation of IPFR. However, when the resistance of SFCL increases to $30 \Omega$, the protection distance shrinks to $68 / 85$ $\mathrm{km}$.

TABLE5

INFLUENCES OF R-SFCL ON IPFR UNDER BC FAULT

\begin{tabular}{cccccc}
\hline \hline & \multicolumn{5}{c}{ Protection distance $(\mathrm{km})$} \\
\cline { 2 - 6 } $\begin{array}{c}\text { SFCL } \\
\text { impedance } \\
\text { value }(\Omega)\end{array}$ & $\begin{array}{c}\text { without } \\
\text { SFCL }\end{array}$ & $\begin{array}{c}\text { with } \\
\text { SFCL }\end{array}$ & $\begin{array}{c}\text { Method } \\
\text { I }\end{array}$ & $\begin{array}{c}\text { adjustment } \\
\text { Method } \\
\text { II }\end{array}$ & $\begin{array}{c}\text { Method } \\
\text { III }\end{array}$ \\
\hline 5 & 83 & 80 & 84 & 84 & 83 \\
10 & 83 & 75 & 86 & 86 & 84 \\
15 & 83 & 67 & 88 & 88 & 84 \\
20 & 83 & 56 & 90 & 90 & 83 \\
25 & 83 & 41 & 94 & 94 & 84 \\
30 & 83 & 21 & $/$ & $/$ & 84 \\
\hline
\end{tabular}

Table 5 shows the relation of IPFR protection distance with SFCL impedance value under unsymmetrical two phases BC fault. It is clear that the protection distance decreases dramatically from $80 \mathrm{~km}$ to $21 \mathrm{~km}$ with SFCL impedance rising.
TABLE6

INFLUENCES OF R-SFCL ON IPFR UNDER BCG FAULT

\begin{tabular}{cccccc}
\hline \hline & \multicolumn{5}{c}{ Protection distance $(\mathrm{km})$} \\
\cline { 2 - 6 } $\begin{array}{c}\text { SFCL } \\
\text { impedance } \\
\text { value }(\Omega)\end{array}$ & $\begin{array}{c}\text { without } \\
\text { SFCL }\end{array}$ & $\begin{array}{c}\text { with } \\
\text { SFCL }\end{array}$ & $\begin{array}{c}\text { Method } \\
\text { I }\end{array}$ & $\begin{array}{c}\text { adjustment } \\
\text { Method } \\
\text { II }\end{array}$ & $\begin{array}{c}\text { Method } \\
\text { III }\end{array}$ \\
\hline 5 & 83 & 83 & 88 & 85 & 84 \\
10 & 83 & 83 & 95 & 87 & 85 \\
15 & 83 & 83 & $/$ & 88 & 84 \\
20 & 83 & 80 & $/$ & 91 & 84 \\
25 & 83 & 76 & $/$ & 94 & 84 \\
30 & 83 & 71 & $/$ & $/$ & 84 \\
\hline
\end{tabular}

Table 6 shows the relation of IPFR protection distance with SFCL impedance value under unsymmetrical two phases to ground BCG fault. The protection distance decreases slightly from $83 \mathrm{~km}$ to $71 \mathrm{~km}$ with SFCL impedance rising to $30 \Omega$.

Compare the simulation results in the above four tables, it can be found that: the installation of SFCL have impact on the protection distance of IPFR regardless of the type of shortcircuit fault. Particularly, SFCL has the largest negative impact on IPFR for two phase BC fault and three phases $\mathrm{ABC}$ fault: for both of them the protection distance declined sharply to $20 \mathrm{~km}$. SFCL affects IPFR to the less extent for one phase to ground AG fault and for two phases to ground fault. In these two cases, the protection distance decreases to $68 / 85 \mathrm{~km}$ and $71 / 85 \mathrm{~km}$ respectively when the impedance of SFCL is $30 \Omega$. The reason is that there are two types of action criterion for IPFR: phase to ground criterion and phase to phase criterion. For AG fault, the operation of IPFR merely depends on the phase to ground criterion. For BC fault, IPFR only depends on the phase to phase criterion. For $\mathrm{ABC}$ and BCG fault, both two criteria may take effect. But for the studied model, it can be deducted that the only phase to phase criterion come into effect for $\mathrm{ABC}$ fault because it shares the same figure as $\mathrm{BC}$ fault. The reason for this is complicated and will be explained in the future paper.

Method I tends to over-compensate the protection distance. Method II doesn't improve the operation of IPFR for ABC and $\mathrm{BC}$ fault compared to Method I, but for the other two types (AG and BCG fault), its compensation effect improves significantly. The explanation is as following. $\mathrm{K}$ factor is the zero-sequence current compensation factor, which only exists in phase to ground criterion. Its definition $\mathrm{K}=\frac{Z_{0}-Z_{1}}{3 Z_{1}} . Z_{0}$ is zero sequence impedance. In the original system, $Z_{0}$ and $Z_{1}$ are the zero-sequence impedance and positive-sequence impedance of lines. When SFCL is introduced to the system, $Z_{0}$ represents the lines' zero sequence impedance plus the SFCL's zero sequence impedance. $Z_{1}$ represents lines' positive-sequence impedance plus the SFCL's positive-sequence impedance. For a symmetrical three phases SFCL, the zero sequence of SFCL is zero, the positive sequence impedance of SFCL is the impedance value of a single phase SFCL. Therefore, the impedance value of SFCL should be added to $Z_{1}$ in the denominator of definition formula for $\mathrm{K}$. Therefore, adjusing $\mathrm{K}$ factor can compensate the protection distance to some extent for the two types of phase to ground fault, namely AG 
and BCG fault. However, both two methods cannot fully adjust the protection distance to the theoretical value $85 \mathrm{~km}$. This is because, from the protective relaying view, the SFCL's impedance characteristics does not match with that of the lines of the system so the integration of SFCL destroys the fundamentals of the power system. As a result, pure theoretical analysis cannot be used to solve the problem of the decreasing protection distance of IPFR with the installation of SFCL. In order to improve the operation of IPFR and adjust the protection distance to an acceptable value, we can only use tremendous simulation tryouts to find such a method- Method III. It is found that if the setting impedance is altered by adding the impedance of SFCL multiplying a compensation factor $\delta=0.85$, and meanwhile the $\mathrm{K}$ factor is revised as did in method II. By changing both setting impedance and $\mathrm{K}$ factor, the results can be very desirable: the protection distance of IPFR reach nearly $85 \mathrm{~km}$ for all four types of short-circuited fault.

\section{CONCLUSION}

This paper studies the influences of the resistive SFCL on the operation of the incremental power frequency relay in transmission line. The main research findings are as follows:

1) The installation of resistive SFCL can limit the shortcircuited fault current effectively. The larger the impedance of SFCL is, the less the fault current are limited to be. This is the main feature of SFCL;

2) Theoretical analysis show that the installation of resistive SFCL causes IPFR operate incorrectly. This include misfunction of IPFR for an inner fault and the malfunction of IPFR for an external fault;

3) Simulation results show that for four types of short circuited fault, either symmetric or asymmetric, SFCL affects the protection distance negatively. The effective protection distance of IPFR decrease with the increase of the SFCL resistance. This effect is particularly seriously for two phases $\mathrm{BC}$ fault and three phases $\mathrm{ABC}$ fault;

4) Desirable compensation to eliminate the negative effect of the integration of SFCL can be achieved by adjusting both $\mathrm{K}$ factor and setting impedances of IPFR;
[6] B. Li, C. Li, F. Guo and Y. Xin, "Overcurrent Protection Coordination in a Power Distribution Network With the Active Superconductive Fault Current Limiter" IEEE Transactions on Applied Superconductivity, volume 24, issue 5, 2014, No.5602004

[7] B. Li, C. Li, F. Guo, Y. Xin, C. Wang and X. Pang, "Coordination of Superconductive Fault Current Limiters With Zero-Sequence Current Protection of Transmission Lines" IEEE Transactions on Applied Superconductivity, volume 24, issue 5, 2014, No. 5602105

[8] W. T. B. de Sousa and A. Polasek and F. A. Silva and R. Dias and A. R. Jurelo and R. de Andrade, "Simulations and Tests of MCP-BSCCO-2212 Superconducting Fault Current Limiters," IEEE Trans. Appl. Supercond., vol. 22, no. 2, April. 2012, Art. no. 5600106.

[9] Hobl, A. and Goldacker, W. and Dutoit, B. and Martini, L. and Petermann, A. and Tixador, P., "Design and Production of the ECCOFLOW Resistive Fault Current Limiter," IEEE Trans. Appl. Supercond., vol. 23, no. 3, Jun. 2013, Art. no. 5601804.

[10] de Sousa, W. T. B. and A. Polasek and R. Dias and C.F.T. Matt and R. de Andrade Jr., "Thermal-electrical Analogy for Simulations of Superconducting Fault Current Limiters," Cryogenics., vol. 62, pages. 97109,2014 , issn. 0011-2275

\section{REFERENCES}

[1] Z. Melhem, "High temperature superconductors (HTS) for energy applications," Woodhead Publishing Limited, 2012, page.265

[2] N. Mathias and S.Michael "High Temperature Superconductor Fault Current Limiters: Concepts, Applications, and Development Status," Supercond. Sci. Technol., vol. 24, no. 3, Jan. 2007, page.15-29

[3] X. Dong, W. Kong and T. Cui, "Fault Classification and Faulted-Phase Selection Based on the Initial Current Traveling Wave" IEEE Transactions on Power Delivery, vol. 24, issue 2, 2009, page.552-559

[4] P.M.Anderson, "Power System Protection" Supercond. Sci. Technol., vol. 24, no. 3, Jan. 2007, page.15-29

[5] J. S. Kim and S. H. Lim and J. C. Kim, "Study on Protection Coordination of a Flux-Lock Type SFCL With Over-Current Relay" IEEE Transactions on Applied Superconductivity, volume 20, issue 3, June 2010, page.11591163

Template version 8.0d, 22 August 2017. IEEE will put copyright information in this area See http://www.iee.org/publications_standards/publications/rights/index.html for more information. 